\section{Risk factors for preterm births in São Luís, Maranhão, Brazil}

\author{
Fatores de risco para prematuridade \\ em São Luís, Maranhão, Brasil
}

Vânia Maria de Farias Aragão 1 Antônio Augusto Moura da Silva 2 Lívia Farias de Aragão ${ }^{1}$ Marco Antônio Barbieri ${ }^{3}$

Heloísa Bettiol 3

Liberata Campos Coimbra 4 Valdinar Sousa Ribeiro 1

\title{
Introduction
}

1 Departamento de Medicina, Universidade Federal do Maranhão, São Luís, Brasil.

2 Departamento de Saúde Pública, Universidade Federal do Maranhão, São Luís, Brasil. 3 Departamento de Puericultura e Pediatria, Faculdade de Medicina de Ribeirão Preto, Universidade de São Paulo, Ribeirão Preto, Brasil. 4 Departamento de Enfermagem, Universidade Federal do Maranhão, São Luís, Brasil.

Correspondence Vânia Maria de Farias Aragão Rua dos Jenipapeiros, Quadra 21, no 18, São Luís, MA 65076-490 Brasil. pedro.aragao@elo.com.br

\begin{abstract}
Preterm birth continues to be one of the main causes of neonatal morbidity and mortality. The objective of the present study was to identify risk factors for preterm birth in São Luis, Maranhão, Brazil. The sample consisted of hospital births at 10 public and private hospitals from March 1, 1997 to February 28, 1998. A total of 2,443 live births were randomly selected, excluding multiple deliveries and stillbirths. Preterm birth rate in São Luís was 12.7\%. Risk factors for preterm delivery were maternal age below 18 years, family income equal to or less than one minimum wagel month,primiparity, vaginal delivery at a public hospital, single mothers (or living without a partner), and absence of prenatal care. The following factors remained associated with preterm birth after multivariate analysis to control for confounding: maternal age below 18 years $(O R=1.9)$, primiparity $(O R=1.5)$, and failure to appear for scheduled prenatal care visits $(O R=1.5)$.
\end{abstract}

Risk Factors; Parturition; Premature Infant
Despite technological advances in the care of preterm newborns in recent decades, prematurity is still one of the main causes of neonatal morbidity and mortality, which result from complications inherent to prematurity itself such as hyaline membrane disease, intracranial hemorrhage, necrotizing enterocolitis, and retinopathy of prematurity 1 . In addition, prematurity presents certain somatic, neurological, and psychological disadvantages throughout life, placing an increased burden on society as a whole 2,3 .

Preterm birth rate has shown variation over time, and no country except France has reported a decline in preterm births 4 . In the United States, an increase in preterm birth rate from $9.4 \%$ in 1980 to $11.4 \%$ in 1997 has been reported 5. In Brazil, few population studies on preterm deliveries are available, mainly due to difficulties in obtaining information on gestational age. Nevertheless, two Brazilian population studies also reported an increase in preterm birth rate: in Pelotas, Rio Grande do Sul, the rate increased from $5.6 \%$ in 1982 to $7.5 \%$ in 1993 6, and in Ribeirão Preto, São Paulo, the rate increased from 7.6 to $13.6 \%$, from $1978-79$ to 19947,8 .

The main causes of preterm delivery are spontaneous premature labor, premature rupture of membranes, and therapeutic induction of labor (indicated on the basis of fetal or ma- 
ternal complications) 9. Recent studies have also suggested genital tract infections, stress, anxiety, and depression as determinants of preterm birth 5 . An association between the indiscriminate use of cesarean sections and increased preterm birth rate has also been observed in Ribeirão Preto 7. However, in most cases the etiology of preterm birth is unknown. Several other variables have been associated with this condition, such as unfavorable socioeconomic status (which can be assessed from family income, educational level, social class, or occupation); black race/skin color; maternal age below 16 and above 35 years; smoking during pregnancy; maternal activity requiring long periods of time in the standing position or substantial physical stress; acute or chronic maternal disease such as renal disease, urinary tract infection, heart disease, lung disease, hypertension, and anemia; a history of preterm delivery or low birth weight children; obstetric factors such as uterine malformations, uterine trauma, placenta previa, abruptio placentae; fetal disorders such as fetal erythroblastosis, fetal distress, or intrauterine growth retardation (which might require preterm delivery); and inadvertently performed early delivery 1,10 .

The objective of the present study was to determine the preterm birth rate and its risk factors in one of the poorest capitals of Brazil São Luís, Maranhão - in an attempt to reduce the gap in epidemiological data regarding this problem in Northeast Brazil. Knowledge of risk factors for preterm birth is important for planning health policies aimed at its prevention, taking local circumstances into account.

\section{Material and methods}

Data obtained from the database of the research project Perinatal Health and MotherChild Health Care in the Municipality of São Luis conducted by the Departments of Public Health, Nursing, and Medicine III, Federal University of Maranhão, were analyzed in the present study. The sample consisted of hospital deliveries at 10 public and private hospitals in São Luís from March 1, 1997 to February 28, 1998. Hospital births comprised some $96.3 \%$ of all births in São Luís in 1996, thus guaranteeing a representative sample. Maternity hospitals with less than 100 deliveries in 1996 were excluded (corresponding to $2.2 \%$ of all deliveries in the city of São Luís during the study period).

The sample size was calculated based on the number of hospital births that occurred in São Luís during 1996 (the year preceding the survey), or 20,092. The minimum sample size was calculated as 1,914 births. This considered a $5 \%$ probability of type I error and $80 \%$ statistical power, working with a $10 \%$ exposure among controls, capable of detecting an odds ratio of 1.50 as significant. The sample was stratified by maternity hospital, with the share being proportional to the number of deliveries at each unit. Systematic sampling was performed at each maternity hospital based on the birth list by order of occurrence, with a sampling interval of seven. A total of 2,443 live births were selected randomly, excluding multiple births and stillbirths.

All mothers received detailed information on the study's objectives, and informed consent was obtained before the interview. Interviews were performed during hospitalization or at home in the case of early discharge, which led to some losses. Other losses occurred due to patient refusal, with total losses corresponding to $5.8 \%$. Newborns were weighed on an electronic scale or on an infant scale periodically calibrated by the research team, and anthropometric measurements were obtained with an Appropriate Health Resources and Technology Action Group (AHRTAG) wooden anthropometer 11.

Gestational age was calculated based on the day of the last normal menstrual period (LNMP) reported by the mother. Since calculation of gestational age based on clinical examination of the newborn was not available for a large portion of the sample, and ultrasound is only performed in a minority of patients, LNMP was the only method available for calculating gestational age. When the mother only recalled the month, day 15 was adopted as the LNMP. Date of LNMP was not reported by 98 women $(4.0 \%)$. Birth weights incompatible with the reported LNMP that were above the 99th percentile of the English curve were reclassified as unknown (50 cases). The same procedure was applied to cases with an implausible gestational age (less than 20 or more than 50 weeks, totaling 22 cases). All 170 cases, corresponding to $7.0 \%$, with LNMP date missing or reclassified as unknown were imputed in a linear regression model 12,13. Birth weight, parity, gender of the neonate, and family income were used to impute gestational age 14. Missing information on gestational age was associated with lower maternal schooling $(\mathrm{p}<0.01)$. Seven cases were imputed as preterm, and the remaining (163) as term birth. Newborns with a gestational age of less than 37 weeks were classified as preterm.

The following variables were studied: birth weight $(<2,500 \mathrm{~g}$ - low birth weight and $\geq 2,500 \mathrm{~g}-$ 
non-low birth weight), birth-weight-for-gestational-age patterns (small-for-gestational-age SGA, birth weight below the 10th percentile; appropriate-for-gestational-age - AGA, weight between the 10th and 90th percentile; largefor-gestational-age - LGA, above the 90th percentile of the reference curve) 15 , smoking during pregnancy (yes or no irrespective of the number of cigarettes smoked per day), maternal age (less than 18, 18 to 19,20 to 24,25 years or more), marital status (married, cohabiting, without a partner), mother's educational level (0 to 4 years, 5 years or more), family income (expressed as times the monthly minimum wage: up to 1,1 to $3,>3)$, parity $(1,2$ to 4,5 or more deliveries), category of the hospital where the patient gave birth (public or private), type of delivery (vaginal or cesarean), presence or absence of low birth weight children from a previous pregnancy, prenatal care (yes - one or more visits, or no-no visit), and occupation of the head of the family (non-manual, semiskilled, unskilled, and unknown).

Data were analyzed using the Stata version 6.0 statistical package. The chi-square test was used to compare proportions, with the level of significance set at 0.05 . Odds ratios with respective $95 \%$ confidence intervals were calculated to determine the effect of each variable on preterm birth. P-values between 0.10 and 0.05 were considered marginally significant. For multivariate analysis, a stepwise logistic multiple regression model with backward elimination was used to control for confounding factors. Variables presenting a $\mathrm{p}$ value below 0.20 on univariate analysis entered the analysis, and those with $\mathrm{p}<0.10$ remained in the model.

\section{Results}

A total of 2,443 singletons born to mothers living in São Luís were studied. Preterm birth rate was $13.1 \%$ before correction and $12.4 \%$ after imputation. Among the socioeconomic variables studied, only family income showed an association with preterm birth $(\mathrm{p}=0.04)$, with the incidence of preterm births being higher in families with a family income of less than one minimum wage (15.5\%). Maternal schooling, occupation of the head of the family, and maternal work were not associated with preterm birth.

Single mothers or those without a partner ( $p=0.078)$, those who did not attend prenatal care $(\mathrm{p}=0.057)$, and those giving birth at a public hospital ( $p=0.079$ ) showed a higher incidence of preterm deliveries, but the signifi- cance was marginal. Cesarean section conferred a marginal protection against preterm birth $(\mathrm{p}=$ 0.050 ). Prevalence of preterm newborns was higher for mothers under 18 years $(22.5 \%)$ and primiparae (15.6\%). Maternal smoking during pregnancy was not associated with preterm births in the present study (Table 1).

After adjustment for confounding factors, age less than 18 years $(\mathrm{p}<0.001)$, primiparity ( $p=0.005)$, and failure to attend scheduled prenatal care visits $(p=0.043)$ remained as risk factors for preterm birth (Table 2). Among preterm newborns, $29.1 \%$ were LGA. The proportion of SGA infants was higher among term (15.2\%) than among preterm newborns (7.1\%) (Table 3$)$.

\section{Discussion}

The literature varies with respect to risk factors for preterm birth, due to differences between the various study populations or different methods used for data collection and analysis. In the present study, mothers with a family income equal to or less than one minimum wage, mothers under 18 years of age, and primiparae showed a higher proportion of preterm children, while mothers without a partner who gave birth at a public hospital, who had vaginal deliveries, and who had not attended prenatal care presented a marginal increase in the proportion of preterm infants. After controlling for confounding factors, maternal age less than 18 years, primiparity, and absence of prenatal care remained as risk factors for preterm birth.

Among socioeconomic factors, only lower family income was associated with increased risk of preterm birth. Kramer 16 has demonstrated an association between a family's socioeconomic conditions and the risk of preterm birth and has suggested that lower income and less schooling are probably not directly related to the duration of pregnancy but lead to unhealthy behaviors and chronic exposure to stress, with a consequent reduction of the duration of pregnancy. In this study, disappearance of the association between family income and preterm birth in the adjusted model suggests that the effects of low family income on preterm birth are possibly mediated by young maternal age and absence of prenatal care.

In the present study, most socioeconomic factors did not show an important influence on preterm birth. Maternal schooling, maternal work outside the home, and occupation of the head of the family were not associated with preterm birth. This finding might be due to a certain socioeconomic homogeneity in the pop- 
Non-adjusted analysis of some risk factors for preterm birth. São Luís, Maranhão, Brazil, 1997-1998.

\begin{tabular}{|c|c|c|c|c|c|c|}
\hline Variable & Total & $\mathrm{n}$ & $\%$ & OR & $95 \% \mathrm{Cl}$ & $\mathrm{p}$ \\
\hline Family income* & & & & & & 0.044 \\
\hline$\leq 1$ & 401 & 62 & 15.5 & 1.32 & $0.95-1.83$ & \\
\hline $1-3$ & 843 & 93 & 11.0 & 0.89 & $0.67-1.19$ & \\
\hline$>3$ & 1,036 & 126 & 12.2 & 1.00 & Reference & \\
\hline Unknown & 163 & 28 & 17.2 & 1.50 & $0.96-2.34$ & \\
\hline Maternal schooling (years) & & & & & & 0.737 \\
\hline $0-4$ & 420 & 51 & 12.1 & 0.94 & $0.69-1.30$ & \\
\hline$\geq 5$ & 2,017 & 257 & 12.7 & 1.00 & Reference & \\
\hline Unknown & 6 & & & & & \\
\hline Marital status & & & & & & 0.620 \\
\hline Married & 704 & 74 & 10.5 & 1.00 & Reference & \\
\hline Cohabiting & 1,146 & 114 & 12.8 & 1.25 & $0.93-1.68$ & \\
\hline Without a partner & 592 & 88 & 14.9 & 1.49 & $1.07-2.07$ & \\
\hline Unknown & 1 & & & & & \\
\hline Maternal work & & & & & & 0.852 \\
\hline Yes & 606 & 78 & 12.9 & 0.97 & $0.74-1.28$ & \\
\hline No & 1,836 & 231 & 12.6 & 1.00 & Reference & \\
\hline Unknown & 1 & & & & & \\
\hline $\begin{array}{l}\text { Occupation of the head } \\
\text { of the family }\end{array}$ & & & & & & 0.879 \\
\hline Non-manual & 503 & 61 & 12.1 & 1.00 & Reference & \\
\hline Semi-skilled & 1,102 & 134 & 12.2 & 1.00 & $0.73-1.39$ & \\
\hline Unskilled & 772 & 99 & 12.8 & 1.07 & $0.76-1.50$ & \\
\hline Unknown & 66 & 10 & 15.2 & 1.29 & $0.63-2.67$ & \\
\hline Hospital category & & & & & & 0.079 \\
\hline Private & 269 & 25 & 9.3 & 1.00 & Reference & \\
\hline Public & 2,174 & 284 & 13.1 & 1.47 & $0.95-2.25$ & \\
\hline Maternal age (years) & & & & & & $<0.001$ \\
\hline$<18$ & 320 & 73 & 22.8 & 2.23 & $1.60-3.10$ & \\
\hline $18-19$ & 399 & 41 & 10.3 & 0.87 & $0.59-1.26$ & \\
\hline $20-24$ & 941 & 110 & 11.7 & 1.00 & Reference & \\
\hline$\geq 25$ & 781 & 85 & 10.9 & 0.92 & $0.68-1.25$ & \\
\hline Unknown & 2 & & & & & \\
\hline Parity & & & & & & $<0.001$ \\
\hline 1 & 1,190 & 186 & 15.6 & 1.68 & $1.31-2.15$ & \\
\hline $2-4$ & 1,148 & 114 & 9.9 & 1.00 & Reference & \\
\hline$\geq 5$ & 105 & 9 & 8.6 & 0.85 & $0.42-1.73$ & \\
\hline Type of delivery & & & & & & 0.050 \\
\hline Vaginal & 1,619 & 220 & 13.6 & 1.00 & Reference & \\
\hline Cesarean & 824 & 89 & 10.8 & 0.77 & $0.59-1.00$ & \\
\hline Prenatal care & & & & & & 0.057 \\
\hline Yes & 2,242 & 275 & 12.3 & 1.00 & Reference & \\
\hline No & 201 & 34 & 16.9 & 1.46 & $0.97-2.15$ & \\
\hline Smoking habit & & & & & & 0.669 \\
\hline Yes & 145 & 20 & 13.8 & 1.11 & $0.68-1.8]$ & \\
\hline No & 2,298 & 289 & 12.6 & 1.00 & Reference & \\
\hline
\end{tabular}

* Expressed as times the monthly minimum wage (one monthly minimum wage = approximately U\$80)

$\mathrm{n}=$ number of preterm newborns; $\mathrm{OR}=$ odds ratio; $95 \% \mathrm{Cl}=95 \%$ confidence interval. 
ulation. Maranhão is one of the poorest states in Brazil. About half the population of São Luís has a family income equal to or less than 3 times the monthly minimum wage, or roughly U $\$ 240$ / month 17 , with this category representing $51 \%$ of the birth population studied here. No association between family income and preterm birth was observed in either Pelotas 6 or $\mathrm{Ri}$ beirão Preto 7 .

According to data from the State Survey on Health, Nutrition, and Infant Mortality (PESN$\mathrm{MI})$, the percentage of adolescent mothers in São Luís was $15.2 \%$ in 1996 18. In contrast, in the present study this rate was much higher (29.4\%), and the highest incidence of preterm newborns $(22.5 \%)$ was observed precisely in this age group, with the adjusted risk of an adolescent mother having a preterm child being 1.9 times that observed for the other age groups. A study on risk factors for preterm birth and low birth weight in the municipality of São Paulo showed that teenage birth does not influence the occurrence of low birth weight infants but leads to a 1.3-fold increase in the risk of preterm delivery 19. A similar situation was observed for primiparae, who presented a 1.5fold risk for the occurrence of premature births, with the same value reported in France in 199520.

Lack of prenatal care was associated with preterm birth in the present study, in agreement with other authors 10,16. Assessment of the quality of care for pregnant women in São Luís detected low coverage, late initiation, and a reduced number of prenatal visits 21 . Lack of prenatal care in Northeast Brazil (26.1\%) is more common than in other regions of the country. Mothers with less schooling have the lowest prenatal care rates 22 . However, serious doubts exist regarding the effect of prenatal care on reducing the risk of preterm birth. It is believed that women with unfavorable socioeconomic conditions actually attend prenatal care less frequently 4 . In the present study, most preterm newborns were born by vaginal delivery, with cesarean section not representing a risk factor for preterm birth. Although the percentage of cesarean sections performed in São Luís was well above that recommended by the World Health Organization 23, corresponding to about $30 \%$ of all births, this value was not as high as that reported for some cities in Southern Brazil (up to $50 \%$ ), where an association between cesarean section and preterm birth has been observed 7,14.

Misclassification of family income and gestational age may have attenuated the association between some variables and preterm birth. Use of the LNMP to date gestations is prone to

\begin{tabular}{|c|c|c|c|}
\hline $\begin{array}{l}\text { Adjusted analysis of risk } \\
\text { Brazil, 1997-1998. }\end{array}$ & erm bir & Luís, Maran & \\
\hline Variable & OR & $95 \% \mathrm{Cl}$ & $P$ \\
\hline Maternal age (years) & & & $<0.001$ \\
\hline$<18$ & 1.89 & $1.33-2.68$ & \\
\hline $18-19$ & 0.78 & $0.53-1.15$ & \\
\hline $20-34$ & 1.00 & Reference & \\
\hline$\geq 35$ & 1.04 & $0.76-1.43$ & \\
\hline Parity & & & 0.005 \\
\hline 1 & 1.56 & $1.19-2.04$ & \\
\hline $2-4$ & 1.00 & Reference & \\
\hline$\geq 5$ children & 0.82 & $0.39-1.70$ & \\
\hline Prenatal care & & & 0.017 \\
\hline Yes & 1.00 & Reference & \\
\hline No & 1.63 & $1.09-2.40$ & \\
\hline
\end{tabular}

$\mathrm{OR}=$ odds ratio $; 95 \% \mathrm{Cl}=95 \%$ confidence interval.

Table 3

Weight for gestational age in preterm and term neonates.

São Luís, Maranhão, Brazil, 1997-1998.

\begin{tabular}{lrrrrr}
\hline Gestational age & Preterm newborn & \multicolumn{2}{c}{ Term newborn } & n \\
& $n$ & $\%$ & $n$ & $\%$ & $<0.001$ \\
\hline Small for gestational age & 22 & 7.1 & 325 & 15.2 \\
Appropriate for gestational age & 197 & 63.8 & 1701 & 79.9 \\
Large for gestational age & 90 & 29.1 & 104 & 4.9 \\
\hline
\end{tabular}

error 4. LNMP information obtained from teenage and low-schooling mothers may be less reliable, since it may be more prone to considering bleeding episodes in early gestation as normal menses and thus underestimate gestational duration 24 .

Thus, the higher preterm birth rate observed in our population may be at least partially due to an artifact. Missing data on gestational age could be another source of bias. In fact, missing data on gestational age differed according to maternal schooling $(\mathrm{p}<0.001)$. Consequently, association between maternal schooling and preterm birth tended to be underestimated. It was not possible to use a clinical estimate of gestational age because it was not available. To minimize the problem of missing data on gestational age, we performed an 
imputation procedure. The results were approximately the same when we used a model with preterm birth excluding missing data, thus not considering imputation.

In the present study, a high incidence of large-for-gestational-age infants, corresponding to $29.1 \%$, was observed among preterm newborns. The classification of gestational age was based on the LNMP reported by the mother. Various factors might have introduced errors into the determination of gestational age by this method, such as irregularities in the menstrual cycle, late ovulation, and vaginal blood loss after conception, causing term newborns to be considered preterm 25 . We did not determine the percentage of infants born to diabetic mothers, another cause of LGA infants, but we believe that this problem did not have a great impact since gestational diabetes is not a very frequent event. Another likely explanation for the large number of large-for-gestationalage preterm newborns, although not confirmed, is the lack of intervention in pregnancies with severe intrauterine growth retardation culminating in intrauterine death, thus reducing the proportion of small-for-gestational-age preterm infants.

We conclude that among social factors, only low family income was associated with a higher risk of preterm birth. Pregnancy during adolescence was a risk factor independently associated with preterm birth in São Luís, and thus all efforts should be concentrated on its prevention. Campaigns encouraging compliance with prenatal care, as well as strategies to improve the quality of this care, should be implemented. Primiparity represents another important risk factor for preterm birth, which, however, cannot be modified by public policies.

\section{Resumo}

A prematuridade continua sendo uma das principais causas de morbidade e mortalidade neonatal. O presente estudo tem como objetivo identificar os fatores de risco para a prematuridade em São Luís, Maranhão, Brasil. Foi estudada uma amostra de partos hospitalares ocorridos em dez hospitais públicos e privados no período de 1o de março de 1997 a 28 de fevereiro de 1998. Foram selecionados 2.443 nascidos vivos de forma aleatória, sendo excluídos os nascimentos de partos múltiplos e os natimortos. A incidência de nascimen tos pré-termo em São Luís foi de 12,7\%. Os fatores de risco para a prematuridade foram: idade materna menor de 18 anos, renda familiar menor ou igual a um salário mínimo, primiparidade, nascer em hospital público e de parto vaginal, viver sem companheiro, e não ter feito pré-natal. Após análise multivariável para controle dos fatores de confundimento, permaneceram associados ao nascimento prematuro: idade materna menor de 18 anos $(O R=1,9)$, primiparidade $(O R=1,5)$ e o não comparecimento ao prénatal $(O R=1,5)$.

Fatores de Risco; Parto; Prematuro

\section{Contributors}

V. M. F. Aragão and L. F. Aragão participated in the data collection and analysis, discussion of the results, and drafting of the article. A. A. M. Silva contributed to the supervision of the statistical analyses and drafting of the article. M. A. Barbieri performed the critical review and approval of the final version of the article. H. Bettiol contributed to the supervision of the statistical analyses and critical review of the content. V. S. Ribeiro and L. C. Coimbra assisted with the supervision of the data collection and analysis of the results.

\section{Acknowledgments}

This study was funded by the Brazilian National Research Council (CNPq) (grants no. 523474/96-2 and 520664/98-1). We thank Julinaide Nunes Matos for valuable collaboration in the elaboration of the present study. 


\section{References}

1. Cloherty JP, Stark AS. Manual de neonatologia. 4a Ed. Rio de Janeiro: MEDSI; 2000.

2. Hediger ML, Overpeck MD, Ruan WJ, Troendle JF. Birthweight and gestational age effects on motor and social development. Paediatr Perinat Epidemiol 2002; 16:36-46.

3. Johnston Jr RB, Williams, MA, Hogue CJR, Mattison DR. Overview: new perspectives on the stubborn challenge of preterm birth. Paediatr Perinat Epidemiol 2001; 15 Suppl 2:3-6.

4. Kramer MS. Preventing preterm birth: are we making progress? Prenat Neonatal Med 1998; 3:10-2.

5. Howse JL. Foreword: march of dimes commitment to solving the problem of prematurity. Paediatr Perinat Epidemiol 2001; 15:1-2.

6. Horta BL, Barros FC, Halpern R, Victora GC. Baixo peso ao nascer em duas coortes de base populacional no Sul do Brasil. Cad Saúde Pública 1996; 12 Suppl 1:27-31.

7. Bettiol H, Rona RJ, Chinn S, Goldani M, Barbieri MA. Factors associated with preterm birth in Southeast Brazil: a comparison of two birth cohorts born 15 years apart. Paediatr Perinat Epidemiol 2000; 14:30-8.

8. Silva AAM, Barbieri MA, Gomes UA, Bettiol H. Trends in low birthweight: a comparison of two birth cohorts separated by a 15 year interval in Ribeirão Preto, Brazil. Bull World Health Organ 1998; 76:73-84.

9. Berkowitz GS, Papiernik KE. Epidemiology of preterm birth. Obstet Gynecol 1993; 15:141-3.

10. Ferraz EM, Gray RH, Cunha TM. Determinants of preterm delivery and intrauterine growth retardation in North-East Brazil. Int J Epidemiol 1990; 19:191-8.

11. Barros FC, Victora CG, Vaugham JP. Epidemiologia da saúde infantil. São Paulo: Editora Hucitec/ Brasília: Fundo das Nações Unidas para a Infância; 1991.

12. Alexander GR, Himes JH, Kaufman RB, Mor J, Kogan M. A United States reference fetal growth. Obstet Gynecol 1996; 87:163-8.

13. Rubin DB. Multiple imputation for nonresponse in surveys. New York: John Wiley \& Sons; 1987.

14. Silva AAM, Lamy Filho F, Alves MT, Coimbra LC, Bettiol H, Barbieri MA. Risk factors for low birth weight in Northeast Brazil: the role of caesarean section. Paediatr Perinat Epidemiol 2001; 15:25764 .
15. Williams RL, Creasy RK, Cunningham GC, Hawes WE, Norris FD, Tashiro M. Fetal growth and perinatal viability in California. Obstet Gynecol 1982; 59:624-32.

16. Kramer MS, Seguin L, Lydon J, Goulet L. Socioeconomic disparities outcome: why do the poor fare so poorly? Paediatr Perinat Epidemiol 2000; 14:194-210.

17. Silva AAM, Coimbra LC, Silva RA, Alves MTSSB, Lamy Filho F, Lamy ZC, et al. Perinatal health and mother-child health care in the municipality of São Luís, Maranhão, Brazil. Cad Saúde Pública 2001; 17:1413-23.

18. Tonial SR, Silva AAM. Saúde, nutrição e mortalidade infantil no Maranhão. São Luís: Universidade Federal do Maranhão/Fundo das Nações Unidas para a Infância/Secretaria de Estado da Saúde; 1997.

19. Vitalle MSS. Adolescência e outros fatores de risco (nível econômico, cuidado pré-natal e tabagismo) como determinantes de prematuridade e baixo peso [Tese de Doutorado]. São Paulo: Escola Paulista de Medicina, Universidade Federal de São Paulo; 2001.

20. Foix-L'Helias L, Blondel B. Changes in risk factors of preterm delivery in France between 1981 and 1995. Paediatr Perinat Epidemiol 2000; 14:314-23.

21. Coimbra LC, Silva AAM. Características das mulheres e assistência pré-natal. In: Alves MTSSB, Silva AAM, organizadores. Avaliação de qualidade de maternidades. São Luís: Fundo das Nações Unidas para a Infância; 2000. p. 25-30.

22. Sociedade Civil Bem-Estar Familiar no Brasil. Pesquisa Nacional sobre Demografia e Saúde 1996. Rio de Janeiro: Sociedade Civil Bem-Estar Familiar no Brasil; 1997.

23. World Health Organization. Appropriate technology for birth. Lancet 1985; 24:436-7.

24. Stevens-Simon C, Roghmann KJ, McAnarney ER. Early vaginal bleeding, late prenatal care, and misdating in adolescent pregnancies. Pediatrics 1991; 87:951-2.

25. Zhang JMB, Bower Jr WA. Birth-weight-for-gestational-age patterns by race, sex, and parity in the United States population. Obstet Gynecol 1995; 86:200-8.

Submitted on $6 /$ Nov/2002

Final version resubmitted on 26/Mar/2003

Approved on $7 / \mathrm{Jul} / 2003$ 